\title{
Mapping Vs30 in Taiwan
}

\author{
Chyi-Tyi Lee * and Bi-Ru Tsai \\ Institute of Applied Geology, National Central University, Chung-Li, Taiwan, ROC
}

Received 16 January 2008, accepted 26 September 2008

\begin{abstract}
The average shear-wave velocity of the upper 30 meters of a soil profile (Vs30) is a key indicator of site response dominating the ground-motion amplification. The primary purpose of this study is to map the distribution of Vs30 in Taiwan using available data and multivariate geostatistical techniques. Data from 230 boring and PS logging at soil and soft rock strong-motion station sites were used to establish the spatial relationship between the shear-wave velocity (Vs) and the $\mathrm{N}$ value of standard penetration test (SPT-N). The resultant model was then used to estimate the shear-wave velocity at each depth of a borehole from the Geo2005 database of the Central Geological Survey (CGS) of Taiwan. Finally, a geostatistical method called "kriging with varying local means" was applied to generate a Vs30 distribution map of Taiwan. The site classification results can be updated for Taiwan's strong-motion stations based on this new Vs30 map and actual site measurements.
\end{abstract}

Key words: Vs30, Shear-wave velocity, Strong ground-motion, Site characteristics, Ground-motion amplification, Geostatistics

Citation: Lee, C. T. and B. R. Tsai, 2008: Mapping Vs30 in Taiwan. Terr. Atmos. Ocean. Sci., 19, 671-682, doi: 10.3319/TAO.2008.19.6.671(PT)

\section{INTRODUCTION}

The average shear-wave velocity of the upper 30 meters of a soil profile (Vs30) is used as an important parameter for most earthquake ground-motion site-effect studies (Boore et al. 1993; Anderson et al. 1996; Castro et al. 1997; BSSC 1998; Park and Elrick 1998). Borcherdt (1994a, b) and Martin and Dobry (1994) recommended that structures be designed based on these properties. The "Next Generation Attenuation of Ground Motions Project" (NGA) of the Pacific Earthquake Engineering Research Center (PEER) have directly used Vs30 for the ground-motion attenuation models (Abrahamson and Silva 2007; Boore and Atkinson 2007; Campbell and Bozorgnia 2007; Chiou and Youngs 2007; Idriss 2007). Vs30 has become very important in the field of ground-motion prediction and site-effect studies.

Based on the available geologic, geomorphologic, and some borehole data, and referring to the 1997 Uniform Building Code (UBC) provisions, Lee et al. (2001) classified 708 free-field strong-motion station sites of the Taiwan Strong-Motion Instrumentation Program (TSMIP). They also published a geologic site class map for the whole of Taiwan. After this publication, the Central Weather Bureau (CWB) of Taiwan completed borehole measurement and PS

\footnotetext{
* Corresponding author
}

E-mail: ct@ncu.edu.tw logging data at 257 strong-motion sites at the end of 2005. Although site classification of these stations has become clear, but that of the other sites and sites between stations remains unknown. To solve this problem, we undertook the present study, utilizing borehole and PS logging data from the 230 soil and soft rock sites and the Geo2005 drilling database of the Taiwan CGS to evaluate Vs30 values for each grid-point, and finally completed a Vs30 map of Taiwan. This paper allows us to estimate Vs30 value and identify a site class for each strong-motion station, and for sites between existing stations. These data have been used in the evaluation of strong ground-motion attenuation of the Pingtung earthquake doublet (Wu et al. 2008).

\section{GEOLOGICAL SETTING}

\subsection{Tectonic Environment}

Taiwan is a mountainous island with an area of $36000 \mathrm{~km}^{2}$ and a highest peak, Yushan, reaching an elevation of $3952 \mathrm{~m}$. Tectonically, Taiwan is on the active collision zone between the Asiatic Continent and the Luzon Arc, where the arccontinent collisions started in the Late Miocene and are still vigorously taking place (Chai 1972; Teng 1990). The region is characterized by active crustal deformation (Bonilla 1975, 1977; Yu et al. 1997), frequent earthquakes (Hsu 1971; Tsai 
et al. 1977), numerous typhoons and high erosion rates (Dadson et al. 2003).

\subsection{Site Geology}

Geologically, the Central Range which dominates the mountainous terrain of Taiwan consists of metamorphic complex and a Paleogene slate belt. Bordering this is the Western Foothills, consisting of Neogene sedimentary formations, and the Eastern Coastal Range, which is also made up of Neogene sedimentary strata (Ho 1975) (Fig. 1).

The Taiwan region has a subtropical climate with an average annual precipitation of about $3000 \mathrm{~mm}$ and an average temperature of about $20^{\circ} \mathrm{C}$. Physical and chemical

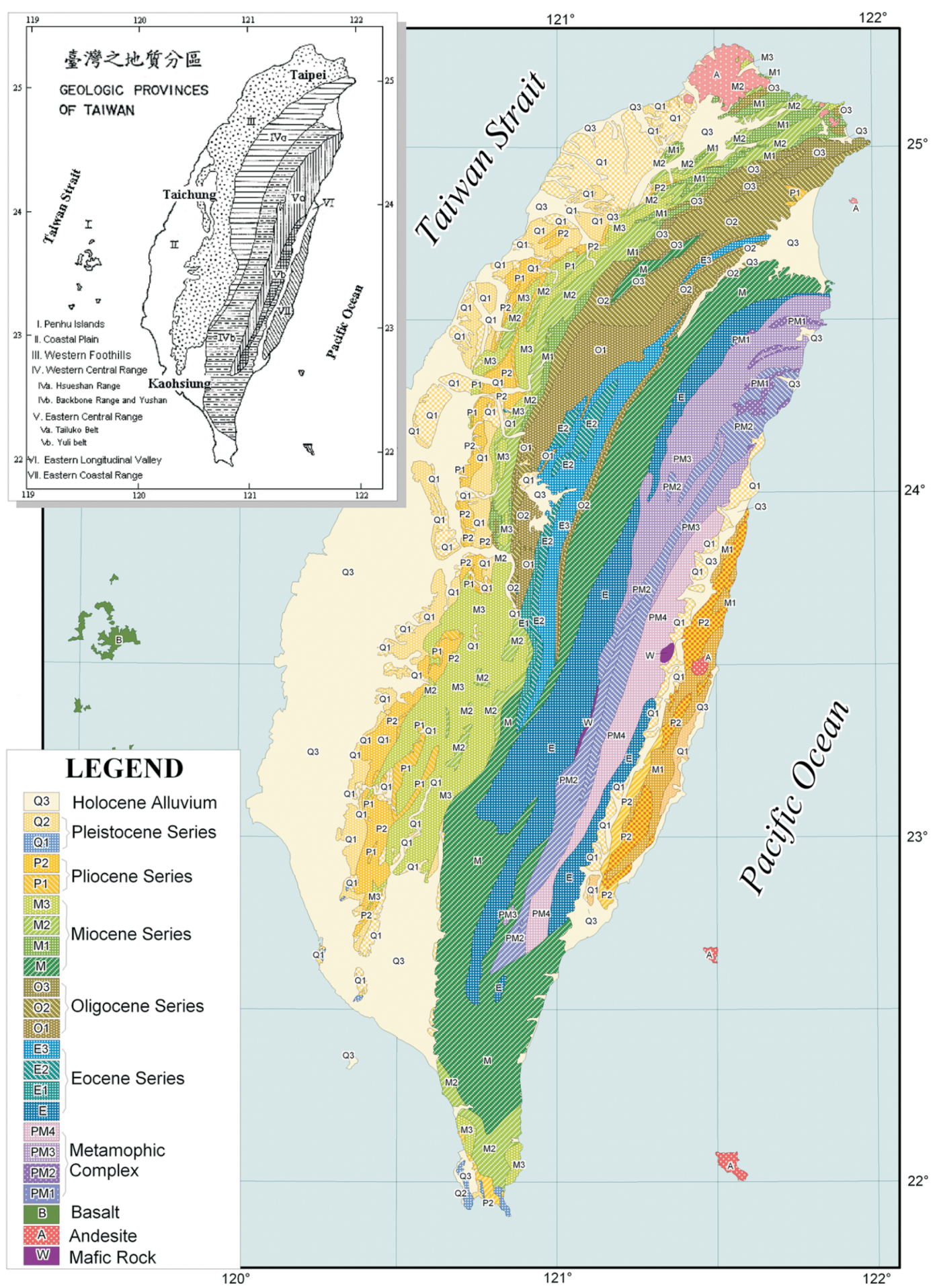

Fig. 1. Generalized geologic map of Taiwan (reduced from the $1: 250000$ - scale geologic map of the CGS). 
weathering are significant and rapid, slope wash and colluvium are widespread on hillsides. Little hard rock exists within a 30-m. depth especially in the built-up areas in this region.

In all of the geological provinces, there are Quaternary alluvial sediments, terrace and basin deposits, and unconsolidated sedimentary strata with a shear-wave velocity of less than $760 \mathrm{~m} \mathrm{~s}^{-1}$. These are the main target with which Vs30 will be evaluated. Miocene and older strata are commonly consolidated rocks with a shear-wave velocity much greater than $760 \mathrm{~m} \mathrm{~s}^{-1}$. Because data are limited and locations are mostly not in built-up area, they are not necessary for inclusion in this geostatistical evaluation.

\section{METHODOLOGY}

\subsection{Work Procedure}

1. We first select borehole data from strong-motion stations where Vs measurements and the N-value of the standard penetration tests (SPT-N) are available.

2. We then establish a shear-wave velocity model based on the selected Vs measurements and the SPT-N.

3. The Vs is estimated at each depth for each available borehole using the shear-wave velocity model.

4. The Vs30 at each strong-motion station and each borehole location is calculated.

5. The Vs30 values at strong-motion stations can be used as the primary variable and the derived Vs30 values at engineering borehole sites can be used as the auxiliary variable in the kriging with varying local means method; interpolations are made for each grid location.

\subsection{Multivariate Geostatistics}

When the number of auxiliary variables is large, multivariate geostatistics may be used to give a better interpolation value at each unknown point from the primary and auxiliary variables. Cokriging with both a primary variable and an auxiliary variable is commonly used in this type of problem (e.g., Krajewski 1987). Kriging with varying local means (Goovaerts 1997) is an alternative method to cokriging, sometimes just called simple cokriging.

In kriging with varying local means, auxiliary variables are used to construct the drift for the kriging system. A regression equation between the primary variable $u$ and the auxiliary variables $v_{j}$ must first be established,

$u=\sum_{\mathrm{j}=1}^{\mathrm{m}} \omega_{j} v_{j}$

Where $\omega_{j}$ is coefficients which can be solved from a set of normal equations. If there is only one auxiliary variable, then the equation becomes, $u_{k}=a v_{k}+b$

From co-located points for the primary variable and the auxiliary variable, the constants $a$ and $b$ may be derived. Using this equation, an auxiliary variable may be transformed to a variable with units similar to the primary variable. The drift for the primary variable may be found from these auxiliary variables using a trend surface analysis,

$u_{k}(x, y)=\sum_{j=0}^{n-1} \sum_{i=0}^{n-j} a_{j}^{i} x^{n-i-j} y^{i}+\varepsilon$

where $n$ represents the order of the trend surface, $\varepsilon$ is an error term.

At each co-located point, the residual of drift or trend is,

$u_{r}=u-u_{k}^{T S}=\sum_{i=1}^{n} \lambda_{i}\left[u_{i}-u_{k, i}^{T S}\right]$

where, $u_{k}^{T S}$ is the drift or trend. The residuals can then be used in ordinary kriging for interpolation. The kriging equation is,

$$
\left\{\begin{array}{l}
\sum_{i=1}^{n} \lambda_{i} \gamma\left(u_{r}^{i}, u_{r}^{j}\right)+\mu=\gamma\left(u_{r}^{i}, u_{r}^{0}\right) \\
\sum_{i=1}^{n} \lambda_{i}=1
\end{array}\right.
$$

where $\gamma$ represents the semivariance of the residuals.

Solving for $\lambda_{i}$, the point estimate for the residual can be done for each grid point. Finally, the residuals are added into the drift to get the final estimates

$u_{0}^{*}=u_{k}^{T S}+\sum_{i=1}^{n} \lambda_{i} u_{r}$

\section{DATA PROCESSING AND ANALYSIS}

\subsection{Selection of Data}

As of the end of 2005, the CWB have finished boring at each of 265 strong-motion sites, and finished PS logging at 257 of them (Fig. 2). An example of a drilling log, the SPT-N and a PS log is shown in Fig. 3. P-wave and S-wave velocity measurements were carried out for each borehole, and at every $0.5 \mathrm{~m}$ a measurement was made by using $\mathrm{OYO}$ PS 170 suspension logger. The time traces of the Vs measurement data were first visually inspected and abnormal record deleted. Then the two traces in a measurement from sources striking in opposite directions and they were checked via cross-correlation analysis. According to these data, they could be classified into 3 different qualities. Quality A rep- 


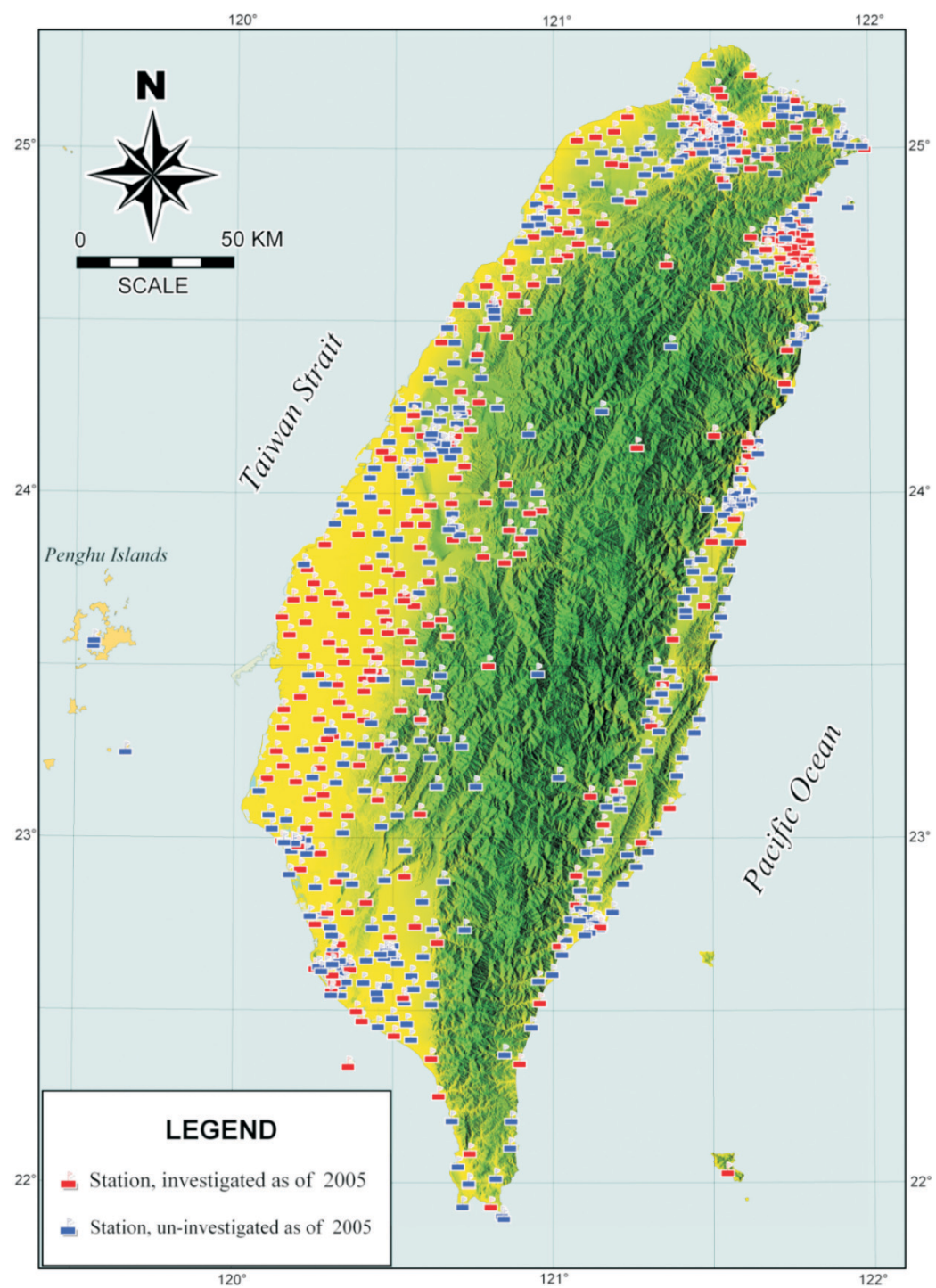

Fig. 2. Topographic relief and strong-motion stations in Taiwan. (The topography is shaded using a $40 \mathrm{~m}$ resolution grid digital terrain model of Taiwan).

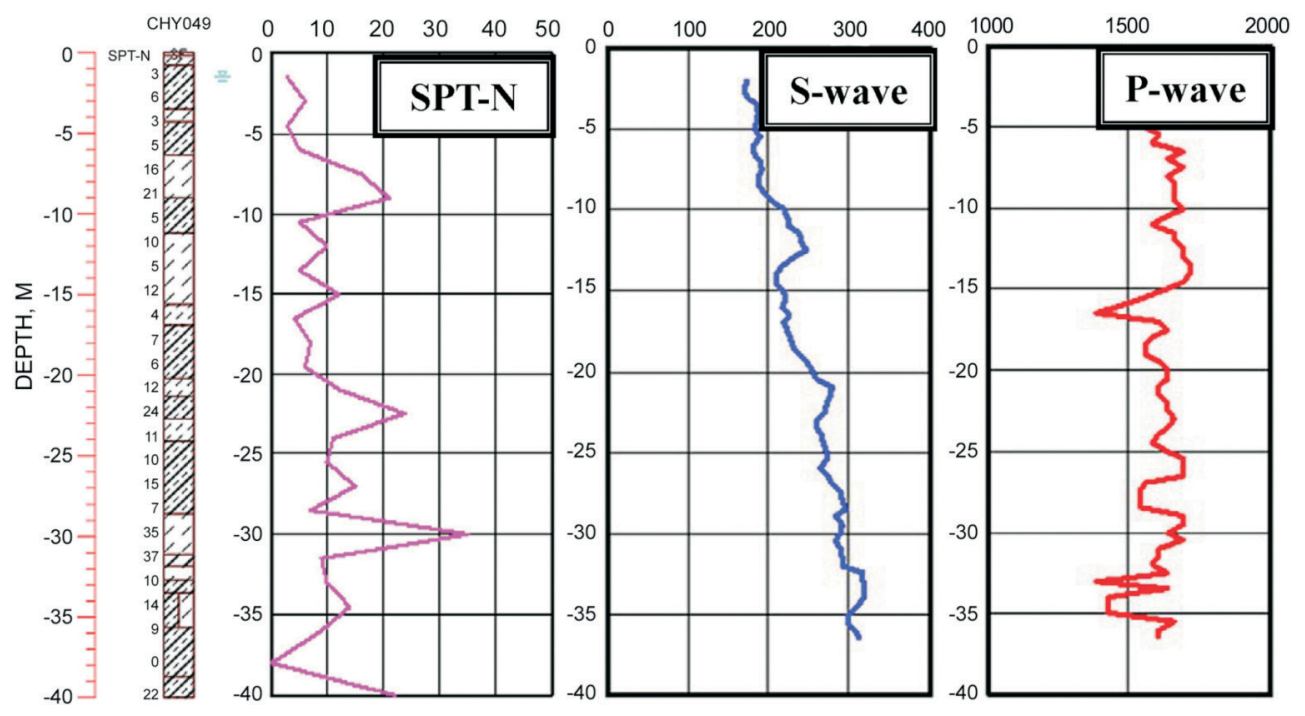

Fig. 3. Example of drilling log, SPT-N and PS logs from Station CHY049 in Tainan. 
resented the best with clear: first arrival and the two traces from the opposite strikes were well correlated (correlation $>0.7$ and time lag $<0.3 \mathrm{~ms}$ ). Only data of quality-A was used for further studies. Examples of the different qualities are shown in Fig. 4.

By the end of the year 2005, the CGS also finished the collection and construction of a database of 19154 engineering exploratory drilling data, including geologic logs, SPT$\mathrm{N}$, and soil laboratory testing results (Geo2005) (Fig. 5). From these, we selected 4885 borehole data with hole-depths greater than or equal to 30 meters, from soil and soft rock sites for calculation of the Vs30.
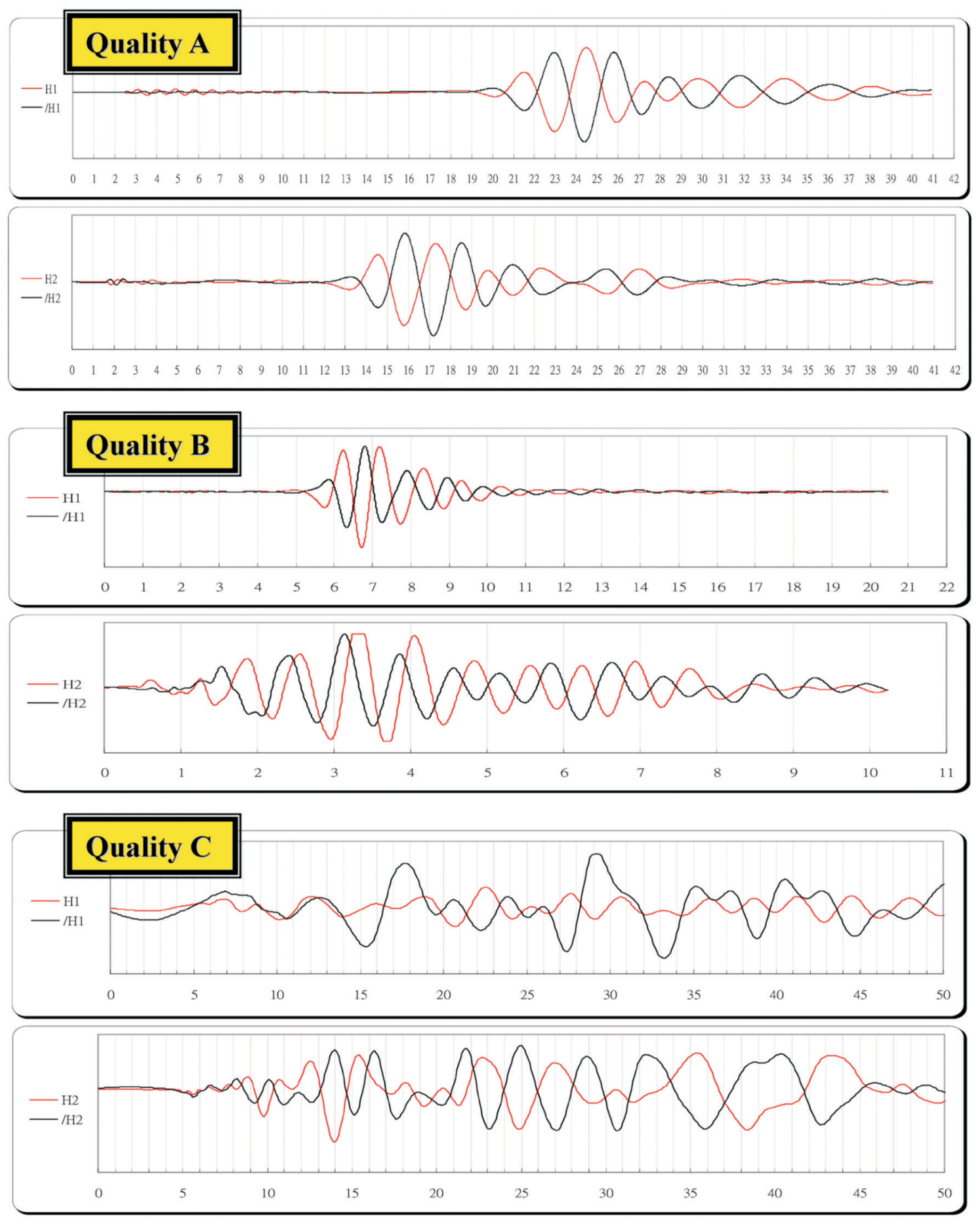

Fig. 4. Examples of 3 different data qualities. Quality A represents the best with clear first arrival and the two traces from the opposite strikes are well correlated (correlation $>0.7$ and time lag $<0.3 \mathrm{~ms}$ ). In the B class, the first arrival is not clear and time lag between the opposite tracks is too large. Losses of correlation and a sharp first arrival characterize quality C. 


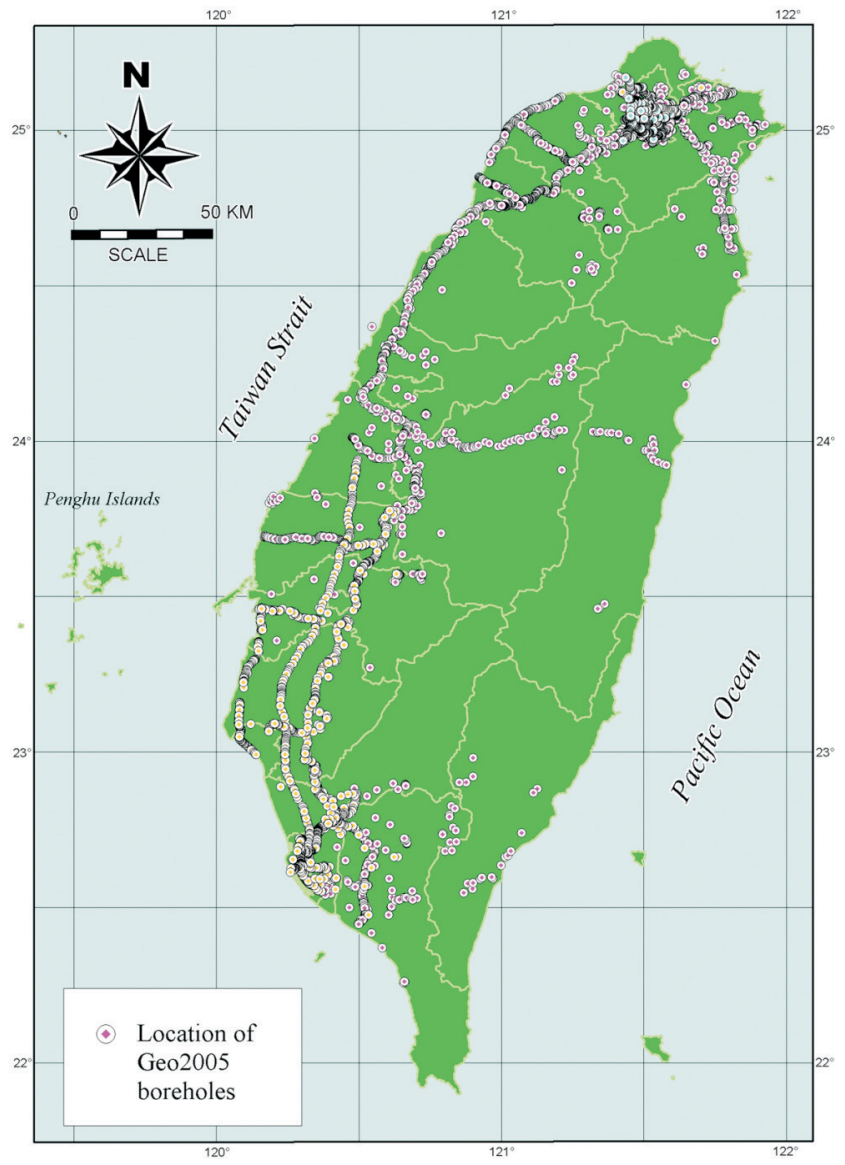

Fig. 5. Locations of exploratory engineering holes in the Geo2005 database.

\subsection{Shear-Wave Velocity Model}

The drilling and PS logging data from 230 strong-motion stations were used to establish the spatial relationship between Vs and SPT-N. SPT-Ns were taken at $1.5 \mathrm{~m}$ intervals, and $\mathrm{Vs}$ at $0.5 \mathrm{~m}$ intervals, therefore the co-location data are spaced $1.5 \mathrm{~m}$ apart. The totally 1127 pairs of data were used in the establishment of the relationship between Vs and SPT-N. According to the grain sizes of soil, one relationship for sand and the other relationship for silt and clay were analyzed (Fig. 6). Gravel, sandy gravels, and any gravel-like content which would cause the SPT blow count to increase abnormally, were not selected for establishing the shearwave velocity models.

During mapping, the whole of Taiwan was divided into 10 homogeneous engineering soil zones and a rocky zone. Miocene and older strata were evaluated and mapped as rock $\left(\mathrm{Vs}>760 \mathrm{~m} \mathrm{~s}^{-1}\right)$. The 10 soil zones were the Northern, Taipei Basin, Taoyuan-Shinchu-Mioli, I-lan Plain, Taichung, Tzuoswei Fan, Alishan, Eastern, Chianan plain, and Kaoping plain zones (Fig. 7). In each homogeneous zone, a Vs and SPT-N relationship was further analyzed to obtain a better fit of the data. For example, the Taipei Basin zone was analyzed using only those data from the 15 strong-motion stations in the Taipei basin (Fig. 8).

\subsection{Kriging with Varying Local Means}

The geostatistical analysis was done zone by zone. The local relationship for a zone was first used to estimate the Vs

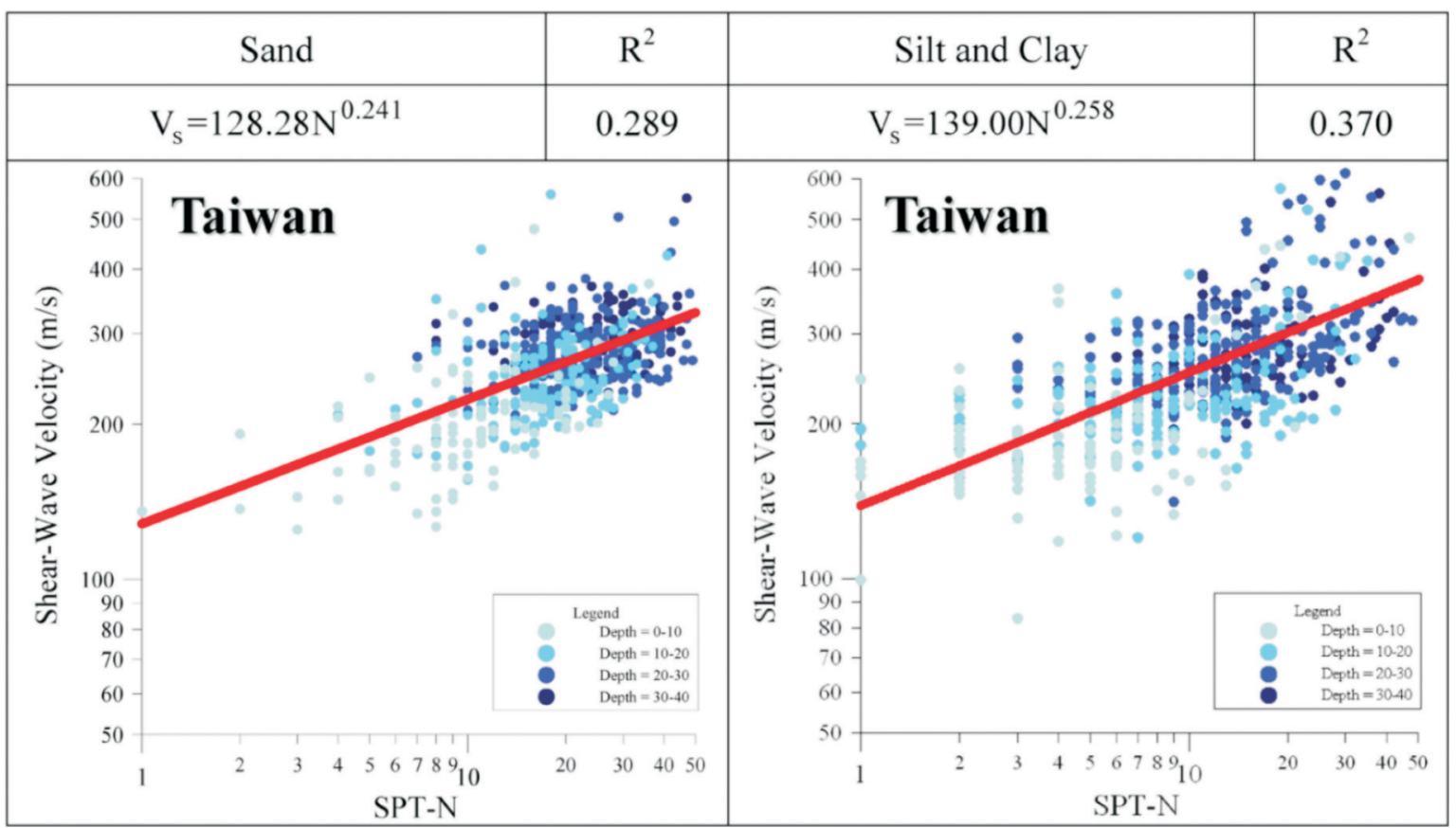

Fig. 6. Shear-wave velocity models for sand and for silt/clay, established from the 1127 good quality Vs and SPT-N paired measurements for 205 holes drilled at soil and soft rock strong-motion station sites. Regression equations and the goodness of fit are shown. 


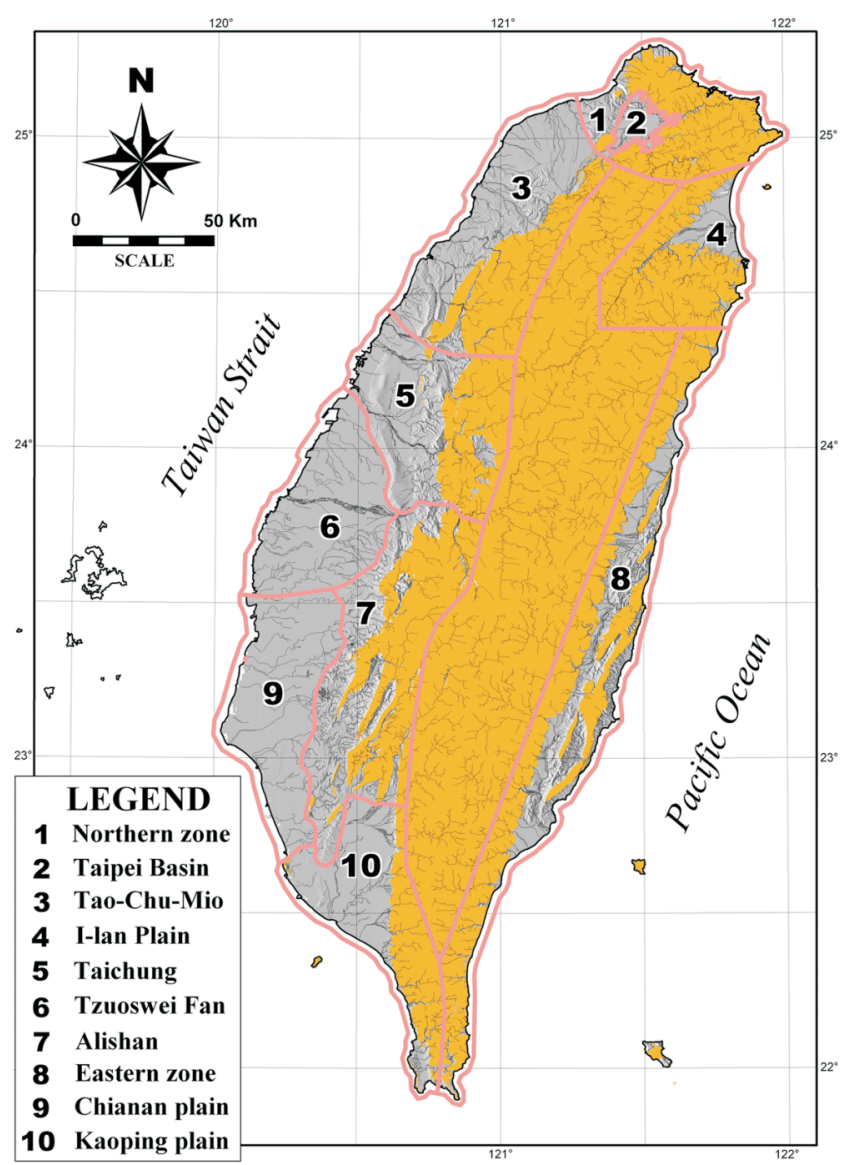

Fig. 7. Ten homogeneous engineering soil zones divided in this study for the purpose of obtaining a better fit of Vs and SPT-N relationship. Rocks which Vs30 are estimated to be greater than $760 \mathrm{~m} \mathrm{~s}^{-1}$ are marked in orange color, and were note used in the geostatistical interpolation. at each depth in a borehole where the SPT-N was available, after which the Vs30 for this location was calculated. These Vs30 values were used as an auxiliary variable to establish the drift for the kriging system. Then residuals in the drift were calculated at each strong-motion site to form a new data set for kriging. Finally, ordinary kriging was done for these residuals, from which a grid map was derived, and these results were added back to the drift to complete the interpolation.

\section{RESULT AND EVALUATION}

\subsection{Vs30 in the Taipei Basin}

A total of 15 strong-motion station boreholes and 844 engineering boreholes were selected in the Taipei Basin. Vs and SPT-N Data from the 15 boreholes were used to establish the shear-wave velocity models for sand and silt/clay, respectively (Fig. 8). The Vs for each depth of the 844 engineering boreholes was estimated from the shear-wave velocity models. Then Vs30 values for 15 strong-motion stations and 844 engineering boreholes in the Taipei Basin were evaluated. The former was used as the primary variable and the latter as the auxiliary variable. The interpolation was accomplished via kriging with varying local means. The results are shown in Fig. 9.

\subsection{Vs30 for the Whole of Taiwan}

In total 230 strong-motion stations and 4885 engineering boreholes were selected from different regions (except rocky zone) of Taiwan. The boreholes for each homogeneous zone are listed in Table 1. The Vs for each

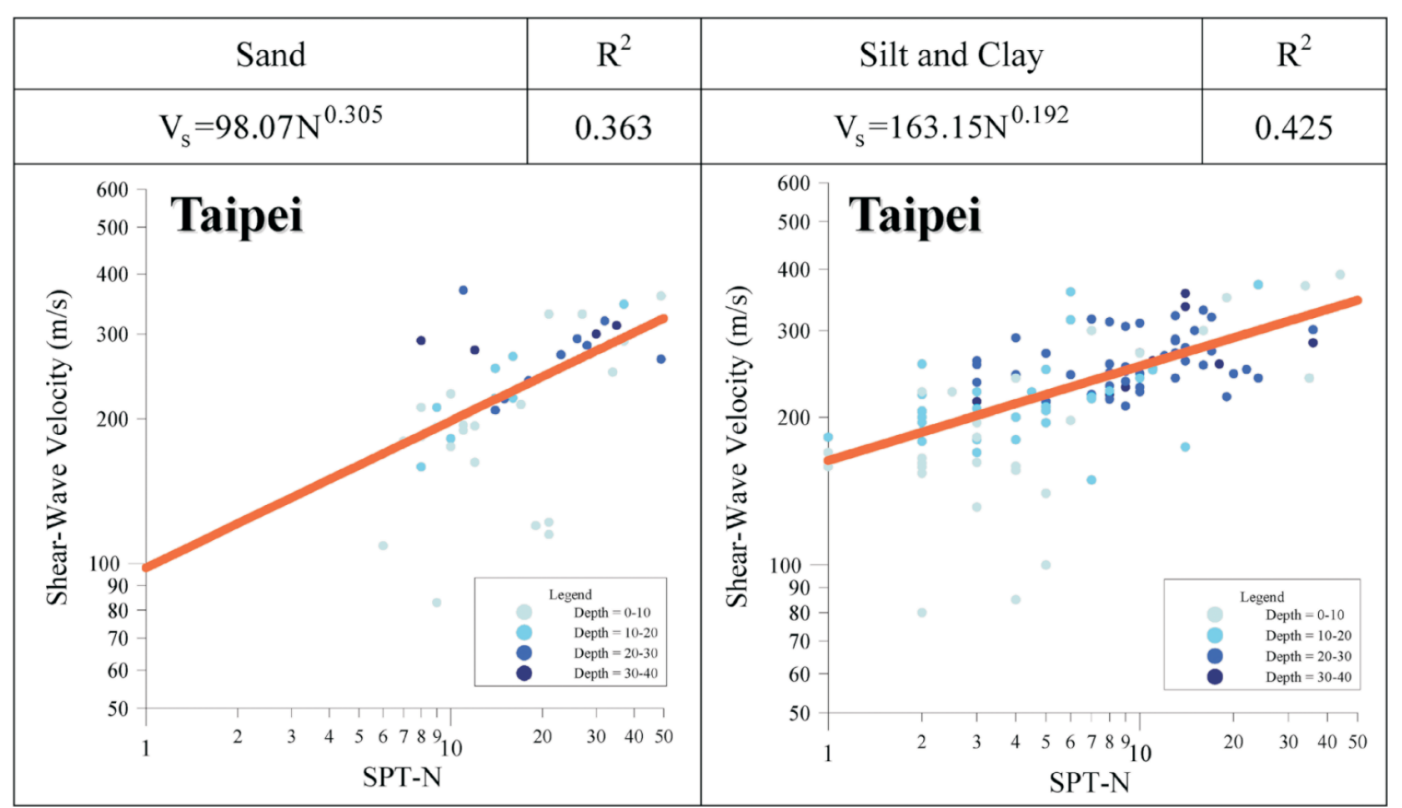

Fig. 8. Shear-wave velocity model for sand and silt/clay, established from the 163 good quality Vs and SPT-N paired measurements for 15 boreholes drilled at the soil and soft rock strong-motion station sites in the Taipei Basin. Regression equations and the goodness of fit are shown. 


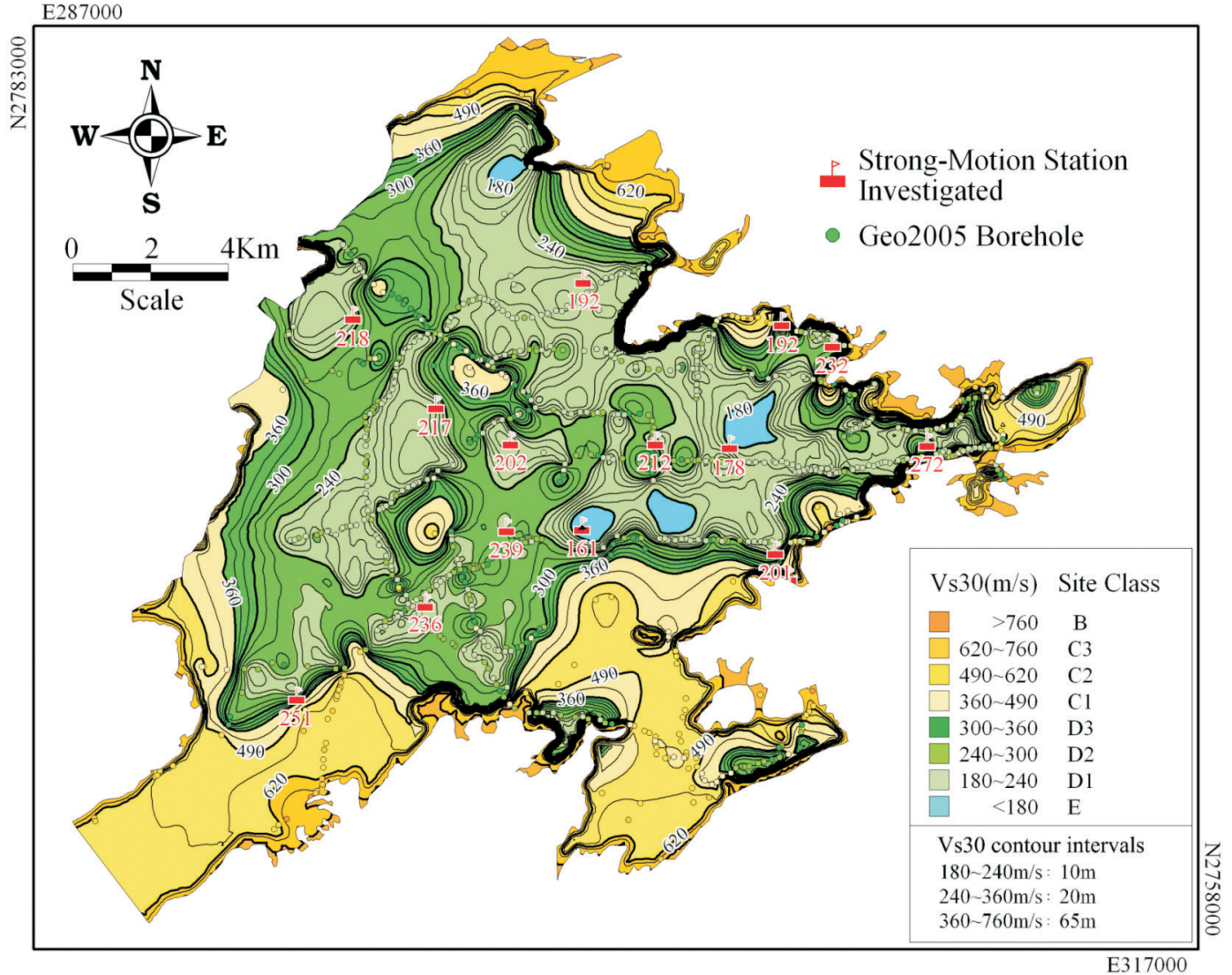

Fig. 9. Vs30 map of Taipei Basin.

Table 1. Number of boreholes in each homogenous zone.

\begin{tabular}{lcc}
\hline Name of homogenous zone & $\begin{array}{c}\text { Number of borehole at } \\
\text { strong-motion station }\end{array}$ & $\begin{array}{c}\text { Number of engineering boreholes } \\
\text { deeper than 30 meters }\end{array}$ \\
\hline Northern zone & $3^{1}$ & 617 \\
Taipei Basin & $15^{1}$ & 844 \\
Taoyuan-Shinchu-Mioli & $34^{1}$ & 974 \\
I-lan Plain & $28^{1}$ & 53 \\
Taichung & $27^{1}$ & 257 \\
Tzuoswei Fan & $43^{1}$ & 597 \\
Alishan & $15^{1}$ & 80 \\
Eastern zone & $13^{1}$ & 39 \\
Chianan plain & $35^{1}$ & 971 \\
Kaoping plain & $17^{1}$ & 453 \\
Sub-total & $\mathbf{2 3 0}$ & $\mathbf{4 8 8 5}$ \\
Rock zone & $27^{1}$ & 130 \\
No PS logging & 8 & - \\
Total & 265 & 5015 \\
\hline
\end{tabular}

*Note: 1: with PS loggings. 
depth in the engineering boreholes was estimated from the shear-wave velocity models established for each homogeneous zone. For some zones (e.g., Northern zone, Taichung zone, and Eastern zone), where testing data from strong-motion stations in that zone was insufficient to establish a shear-wave velocity model, the slope in the model for the whole of Taiwan (Fig. 6) was adopted, and regress as an intercept only. Then evaluation of the Vs30 was done hole by hole.

The kriging with varying local means method was applied to each homogeneous zone using the Vs30 values for strong-motion stations as the primary variable and the Vs30 values for engineering boreholes as the auxiliary variable. The result for each homogeneous zone is a Vs30 grid map. These grid maps were mosaicked to form one single map the Vs30 map of Taiwan is shown in Fig. 10. An 1 to 400000 scale Vs30 map of Taiwan is available at the webpage: http://
tecdc.earth.sinica.edu.tw/data/EQ2006Pingtung/data_note/ LeeCT/Vs30Map_A0.pdf.

\subsection{Site Classification}

Using the available geologic and geomorphologic data, some borehole data, as well as the 1997 Uniform Building Code (UBC) provisions, Lee et al. (2001) classified 708 free-field strong-motion station sites for the Taiwan StrongMotion Instrumentation Program (TSMIP). Of these 708 sites, the Vs30 could be evaluated for 256 sites from actual good quality Vs data and SPT-N (when good quality Vs data was not available). For the other sites, the Vs30 was extracted from the Vs30 Map of Taiwan. The Vs30 values and revised site classification of all 711 free-field strongmotion station sites in Taiwan can be seen at: http://tecdc .earth.sinica.edu.tw/data/EQ2006Pingtung/data_note/LeeC

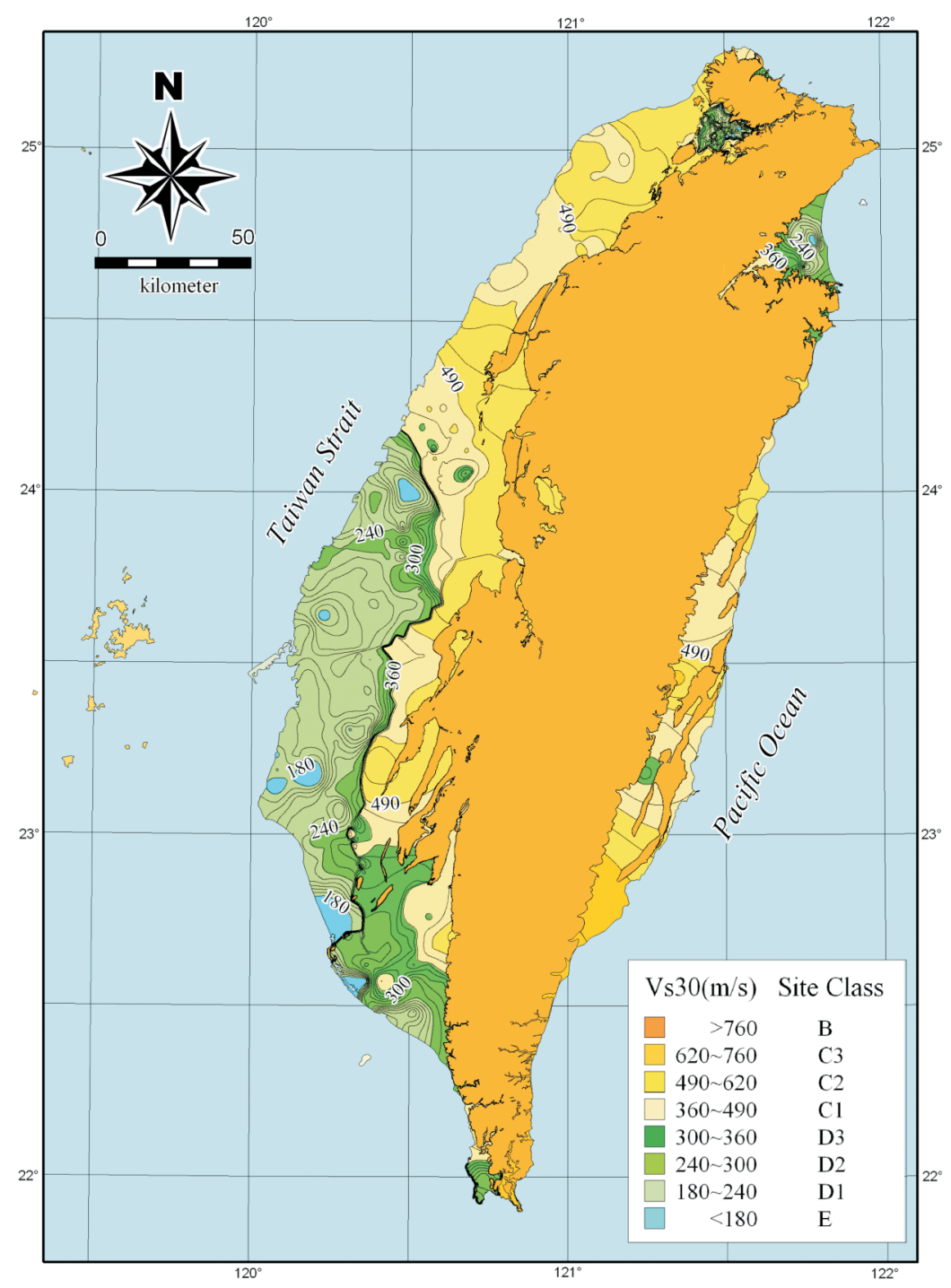

Fig. 10. Vs30 map of Taiwan. 
T/Vs30Table.xls. The Vs30 ranges used for site classification are listed in Table 2.

\section{DISCUSSION}

The results presented above are based on Vs measurements and SPT-N data from all boreholes. Among the data, the large amount of SPT-N data may dominate the results. One may argue that the SPT-N values may increase with the overburden pressure and need correction (Liao and Whitman 1985). However, the Vs also increases with overburden pressure. This means that both the SPT-N and Vs increase with in-situ confining pressure. When establishing the shearwave velocity model via Vs and SPT-N, there is no need to correct for overburden pressure as in the conventional procedure. We have tested this by utilizing the method proposed by Liao and Whitman (1985) to correct for overburden pressure on the SPT-N. The corrected values were used in a regression process for the model, but the results were even worse in terms of goodness of fit (Tsai 2007, Appendix E). Therefore, no overburden pressure correction appeared to be needed for the SPT-N with the shear-wave velocity model. We also considered the depth factor in the shear-wave velocity model, but the improvement of the goodness of fit was limited. Therefore, we adopted a simple logarithmic model between the SPT-N and the Vs.

The Vs measurements, although fewer in number than the SPT-Ns, directly controlled the absolute value of the final results. The quality of the Vs measurements is thus very important. We carefully examined each original record, and set strict criteria for the selection of high quality data. Only about half of the 16287 Vs measurements fit our quality-A criteria and were finally selected to establish the shear-wave velocity model. This quality control ensures the reliability of the Vs30 evaluation.

Table 2. Ranges of Vs30 used in site classification.

\begin{tabular}{|c|c|c|}
\hline Site Class ${ }^{1}$ & Description & Range of $\mathrm{Vs}^{3} 0^{1}$ \\
\hline A & Hard Rock & $>1500 \mathrm{~m} \mathrm{~s}^{-1}$ \\
\hline B & Rock & $760 \sim 1500 \mathrm{~m} \mathrm{~s}^{-1}$ \\
\hline $\mathrm{C} 3$ & \multirow{3}{*}{$\begin{array}{l}\text { Very dense soil } \\
\text { and soft rock }\end{array}$} & $620 \sim 760 \mathrm{~m} \mathrm{~s}^{-1}$ \\
\hline $\mathrm{C} 2$ & & $490 \sim 620 \mathrm{~m} \mathrm{~s}^{-1}$ \\
\hline $\mathrm{C} 1$ & & $360 \sim 490 \mathrm{~m} \mathrm{~s}^{-1}$ \\
\hline D3 & \multirow{3}{*}{ Stiff soils } & $300 \sim 360 \mathrm{~m} \mathrm{~s}^{-1}$ \\
\hline D2 & & $240 \sim 300 \mathrm{~m} \mathrm{~s}^{-1}$ \\
\hline D1 & & $180 \sim 240 \mathrm{~m} \mathrm{~s}^{-1}$ \\
\hline $\mathrm{E}$ & Soft soils & $<180 \mathrm{~m} \mathrm{~s}^{-1}$ \\
\hline
\end{tabular}

*Note: 1: After FEMA (1994).
Kriging with varying local means method is a simplified cokriging method. Although the estimation result are similar, estimation error is not complete from the former method (error from the drift was neglected). Because the Taiwan geology is so complicated, we had to divide it into homogeneous zones to improve the spatial correlation of each factor, and the cross correlation between two factors. In some zones, the data set was indeed too small to establish semivariograms and a cross-semivariogram, so that performing cokriging was simply not possible. The kriging with varying local means method is easier in terms of procedure and still valid for a small data set. It is also valid for more than one auxiliary variable and is more applicable for future development of the multivariate problem.

This study was actually performed in two stages. In the first stage, only 1127 good quality and paired Vs and SPT-N measurements from 205 boreholes made in soil and soft rock strong-motion station sites, completed before 2005, were used to establish the shear-wave velocity models and Vs30 mapping. In the second stage, 1557 new Vs measurements with 1006 A-quality data from 25 additional boreholes drilled at soil and soft rock strong-motion station sites in the year 2005 were used. These additional data were first used for validation purposes, and then included in the mapping. The results of validation show that: (1) there was no need to modify the shear-wave velocity models; (2) the first-stage mapping result was reliable. Adding the 25 new Vs30 data (primary variable) to the geostatistical interpolation only increased the detail around the new data points.

Compared to the site classification results of Lee et al. (2001), the new Vs30 map of Taiwan is basically similar to the old site classification map in pattern, with the values (Vs30) increased, and the E class sites decreased. Lee et al. (2001) used SPT-N values from some boreholes to evaluate the site class; a site with average SPT-N value less than 15 in the top 30 meters of depth was classified as E class. However, in the new shear-wave velocity models, an SPT-N of 15 may mean shear-wave velocity higher than $200 \mathrm{~m} \mathrm{sec}^{-1}$ (See Figs. 6, 8). The same SPT-N value may indicate a higher shear-wave velocity in Taiwan than that in California. This would be the main reason for the reduction in area of the $\mathrm{E}$ class in the new Vs30 map of Taiwan.

\section{CONCLUSIONS AND RECOMMENDATIONS}

We utilized the presently available data to develop a Vs30 map of Taiwan, and updated the classification proposed by Lee et al. (2001) at the free-field strong-motion station sites of Taiwan Strong-Motion Instrumentation Program (TSMIP). Two shear-wave velocity models, for sand and silt/clay, were developed for each mapped zone. The mapping results are reliable, provided validation has been made using the 2005 Vs measurements. However, the ac- 
curacy of this map is naturally primarily dependent on the amount and quality of data. In eastern Taiwan and the southern tip of Taiwan, where data points (boreholes) are few and scattered, the accuracy of the map is relatively lower.

The new Vs30 map is primarily similar in general pattern to the 2001 map by Lee et al. (2001), which did not include any shear-wave velocity measurement data. This study found that the same SPT-N value may indicate a higher shear-wave velocity in Taiwan than that in California, which is the reason for the reduction in the area of the E class in the Vs30 map of Taiwan.

The TSMIP drilling project is still going on; therefore new Vs measurements will be made available as the CWB project progresses. The Vs30 map presented here may be further refined and the site classification of the strong-motion stations updated based on this new data. Eventually, all the strong-motion station sites $(>700)$ will be drilled and measured, but in the meantime, this Vs30 map may supply the up-to-date knowledge for each strong-motion station, and for sites between stations in Taiwan, and applicable for engineering and other research purposes.

Acknowledgements The authors extend our deepest thanks to the Seismology Center of the Central Weather Bureau and National Center for Research on Earthquake Engineering, Taiwan, for providing the drilling and PSlogging data from the strong-motion sites. Out thanks are also given to the Central Geological Survey, Taiwan, for providing the borehole data. This research was supported by the Taiwan Earthquake Research Center (TEC) funded through the National Science Council (NSC) with Grant Number NSC95-2119-M-008-029. The TEC contribution number for this article is 00033 .

\section{REFERENCES}

Abrahamson, N. A. and W. J. Silva, 2007: Abrahamson-Silva NGA ground motion relations for the geometric mean horizontal component of peak and spectral ground motion parameters. PEER Report. Berkeley, Calif.: Pacific Earthquake Engineering Research Center, University of California, $387 \mathrm{pp}$.

Anderson, J. G., Y. Lee, Y. Zeng, and S. Day, 1996: Control of strong motion by the upper 30 meters. Bull. Seismol. Soc. Am., 86, 1749-1759.

Bonilla, M. G., 1975: A review of recently active fault in Taiwan. US Geological Survey Open-File Report 75-41, $58 \mathrm{pp}$.

Bonilla, M. G., 1977: Summary of Quaternary faulting and elevation changes in Taiwan. Mem. Geol. Soc. China, 2, 43-55.

Boore, D. M. and G. M. Atkinson, 2007: Boore-Atkinson NGA ground motion relations for the geometric mean horizontal component of peak and spectral ground motion parameters. PEER Report. Berkeley, Calif.: Pacific Earthquake
Engineering Research Center, University of California, $242 \mathrm{pp}$.

Boore, D. M., W. B. Joyner, and T. E. Fumal, 1993: Estimation of response spectra and peak accelerations from Western North American earthquakes: An interim report. US Geological survey Open-File Report, 93-509.

Borcherdt, R. D., 1994a: Estimates of site-dependent response spectra for design (methodology and justification). Earthq. Spectra, 10, 617-653.

Borcherdt, R. D., 1994b: An integrated methodology for estimates of site-dependent response spectra, seismic coefficients for site dependent building code provisions, and predictive GIS maps of strong ground shaking. In: Proceedings of Seminar on New Developments in Earthquake Ground Motion Estimation and Implications for Engineering Design Practice. Applied Technology Council, ATC, 35-1, 10.1-10.44.

BSSC (Building Seismic Safety Council), 1998: 1997 Edition NEHPR Recommended Provisions for Seismic Regulations for New Buildings and Other Structures, FEMA 302/ 303, Part 1 (Provisions) and Part 2 (Commentary), developed for the Federal Emergency Management Agency, Washing, DC, 337 pp.

Campbell, K. W. and Y. Bozorgnia, 2007: Campbell-Bozorgnia NGA Ground Motion Relations for the Geometric Mean Horizontal Component of Peak and Spectral Ground Motion Parameters, PEER Report. Berkeley, Calif.: Pacific Earthquake Engineering Research Center, University of California, $246 \mathrm{pp}$.

Castro, R. R., M. Mucciarelli, F. Pacor, and C. Petrungaro, 1997: S-wave site-response estimates using horizontal-tovertical spectral rations. Bull. Seismol. Soc. Am., 87, 256260.

Chai, B. H. T., 1972: Structure and tectonic evolution of Taiwan. Am. J. Sci., 272, 389-422.

Chiou, B. S.-J. and R. R. Youngs, 2007: Chiou-Youngs NGA ground motion relations for the geometric mean horizontal component of peak and spectral ground motion parameters. (forthcoming) PEER Report. Berkeley, Calif.: Pacific Earthquake Engineering Research Center, University of California, 219 pp.

Dadson, S. J., N. Hovious, H. Chen, B. W. Dade, S .D. Willett, J. C. Hu, M. J. Horng, M. C. Chen, C. P. Stark, D. Lague, and J. C. Lin, 2003: Links between erosion, runoff variability, and seismicity in the Taiwan orogen. Nature, 426, 648-651.

FEMA 222A, 1994: NEHRP recommended provisions for the development of seismic regulations for new buildings, 1994 edition, Part 1 - provisions, Federal Emergency Management Agency, 290 pp.

Goovaerts, P., 1997: Geostatistcs for Natural Resources Evaluation, Oxford University Press, 483 pp.

Ho, C. S., 1975: An introduction to the geology of Taiwan, explanatory text of the geologic map of Taiwan. Ministry of Economic Affairs, Republic of China, 312 pp. 
Hsu, M. T., 1971: Seismicity of Taiwan and some related problem. The International Institute of Seismology and Earthquake Engineering, Tokyo, Japan, 8, 41-160.

Idriss, I. M., 2007: Empirical model for estimating the average horizontal values of pseudoabsolute spectral accelerations generated by crustal earthquakes, Volume 1, Sites with $\mathrm{Vs} 30=450$ to $900 \mathrm{~m} / \mathrm{s}$. Interim project report. Berkeley, Calif.: Pacific Earthquake Engineering Research Center, University of California, $76 \mathrm{pp}$.

Krajewski, W. F., 1987: Cokriging radar-rainfall and rain gage data. J. Geophys. Res., 92, 9571-9580.

Lee, C. T., C. T. Cheng, C. W. Liao, and Y. B. Tsai, 2001: Site classification of Taiwan free-field strong-motion stations. Bull. Seismol. Soc. Am., 91, 1283-1297.

Liao, S. and R. V. Whitman, 1985: Overburden correction factors for SPT in sand. J. Geotech. Eng., ASCE, 114, 373-377.

Martin, G. R. and R. Dobry, 1994: Earthquake site response and seismic code provisions. NCEER Bull., 8, 1-6.
Park, S. and S. Elrick, 1998: Predictions of shear-wave velocities in southern California using surface geology. Bull. Seismol. Soc. Am., 88, 677-685.

Teng, L. S., 1990: Geotectonic evolution of late Cenozoic arc-continent collision in Taiwan. Tectonophysics, 183, 67-76.

Tsai, B. R., 2007: Further study for site classification of Taiwan free-field strong-motion station. Master Thesis, Institute of Applied Geology, National Central University, Chung-Li, Taiwan, ROC, 205 pp.

Tsai, Y. B., T. L. Teng, J. M. Chiu, and H. L. Liu, 1977: Tectonic implications of the seismicity in the Taiwan region. Mem. Geol. Soc. China, 2, 13-41.

Wu, C. F., W. H. K. Lee, and D. M. Boore, 2008: Strong-motion data from the two Pingtung, Taiwan, earthquakes of $26 \mathrm{De}-$ cember 2006. Terr. Atmos. Ocean. Sci., 19, 595-639, doi: 10.3319/TAO.2008.19.6.595(PT).

Yu, S. B., H. Y. Chen, and L. C. Kou, 1997: Velocity field of GPS stations in the Taiwan area. Tectonophysics, 274, 41-59. 